Fixed Point Theory, 22(2021), No. 2, 761-778

DOI: $10.24193 /$ fpt-ro.2021.2.49

http://www.math.ubbcluj.ro/ nodeacj/sfptcj.html

\title{
FIXED POINT THEOREMS IN THE STUDY OF OPERATOR EQUATIONS IN ORDERED BANACH SPACES AND THEIR APPLICATIONS
}

\author{
SALIMA MECHROUK \\ Faculty of Sciences, UMBB, Boumerdes, Algeria \\ E-mail: mechrouk@gmail.com and s.mechrouk@univ-boumerdes.dz
}

Abstract. We use fixed point index properties and the general minorant principle (see Theorem 7.B in [12]) to prove new fixed point theorems for operators leaving invariant a cone in a Banach space. Main ideas of this work are inspired from the work in [11]. The results obtained are used to prove existence of at least one positive solution to a $\phi$-laplacian boundary value problem.

Key Words and Phrases: Cones, fixed point theory, positive solution, general minorant principle, boundary value problem.

2020 Mathematics Subject Classification: 47H10, 47H11, 34B15.

Acknowledgement. The author would like to thank the Ministry of Higher Education and Scientific Research and his laboratory, Fixed Point Theory and Applications, for supporting this work.

\section{REFERENCES}

[1] H. Amann, Fixed point equations and nonlinear eigenvalue problems in ordered Banach spaces, SIAM Rev., 18(1976), 620-709.

[2] H. Amann, Fixed points of asymptoticaly linear maps in ordered Banach spaces, J. Funct. Anal., 14(1973), 162-171.

[3] N. Benkaci-Ali, A. Benmezai, S. Ntouyas, Eigenvalue criteria for existence of positive solutions to singular third-order BVPs via the index-jump property, Comm. Appl. Nonl. Anal., 20(2013), no. 2, 55-74.

[4] A. Benmezai, B. Bouchenb, J. Henderson, S. Mechrouk, The index-jump property for 1homogeneous positive maps and fixed point theorems in cones, Nonlinear Funct. Anal., (2017), Article ID 6, 1-33.

[5] A. Benmezai, J.R. Graef, L. Kong, Positive solutions for the abstract Hammerstein equations and applications, Commun. Math. Anal., 16(2014), no. 1, 47-65.

[6] A. Benmezai, S. Mechrouk, Positive solutions for the nonlinear abstract Hammerstein equation and application to $\phi$-Laplacian BVPs, NoDEA, 20(2013), 489-510.

[7] K. Deimling, Nonlinear Functional Analysis, Springer-Verlag, 1985.

[8] M.S. El Khannoussi, A. Zertiti, Topological methods in the study of positive solutions for operator equations in ordered Banach spaces, Electronic Journal of Differential Equations, 2016(2016), no. 171, 1-13.

[9] D. Guo, V. Lakshmikantham, Nonlinear Problems in Abstract Cones, Academic Press, Boston, 1988. 
[10] M.A. Krasnosel'skii, Positive Solutions of Operator Equations, P. Noordhoff, Gröningen, 1964.

[11] S. Mechrouk, Fixed point theorems in cones and application, Mediterr. J. Math., 59(2020), $1-20$.

[12] E. Zeidler, Nonlinear Functional Analysis and its Applications, Vol. I, Fixed Point Theorems, Springer Verlag, New York 1986.

Received: September 24, 2019; Accepted: January 7, 2020. 
FIXED POINT THEOREMS IN THE STUDY OF OPERATOR EQUATIONS 